\title{
Factors associated with spontaneous preterm birth in Addis Ababa public hospitals, Ethiopia: cross sectional study
}

\author{
Ababe Tamirat Deressa ${ }^{1 *}$, Amsale Cherie ${ }^{2}$, Teshome Melese Belihu ${ }^{3}$ and Gemechu Ganfure Tasisa ${ }^{4}$
}

\begin{abstract}
Background: Spontaneous preterm birth is commencement of labor with intact or pre labor rapture of membrane and birth before 37 weeks of gestation. The aim of this study was to identify common factors associated with spontaneous preterm birth in Addis Ababa public hospitals.

Methods: After random selection of three hospitals from the six Addis Ababa's Public hospitals having Neonatal intensive care unit, systematic sampling was employed to select study units from admission log book of the neonates. Data were collected using structured checklist. Finally, data entered to EpiData 3.1 and transported to SPSS 22 for analysis. Bivariate and multivariate logistic regression analysis was done for the variables.

Result: The mean gestational age of preterm birth was 32.45 ( \pm 2.903 SD). Majority $(66.1 \%)$ of preterm births were spontaneous and 33.9\% were induced preterm births. Hypertension during pregnancy $[P=0.001, A O R=0.182,95 \%$ Cl: $(0.067,0.493)]$ and maternal HIV infection $[P=0.041, A O R=3.40895 \% \mathrm{Cl}:(1.048,11.079)]$ significantly associated with spontaneous preterm birth.

Conclusion: Those mothers who were diagnosed with hypertension during pregnancy less likely gave spontaneous preterm birth than who had no history of hypertension during pregnancy and HIV positive mothers gave spontaneous preterm more likely than HIV negative mothers. Thus, giving emphasis to these factors with appropriate care during pregnancy is important to reduce spontaneous preterm birth.
\end{abstract}

Keywords: Preterm birth, Spontaneous, Factors, Addis Ababa

\section{Background}

Preterm birth is defined as a delivery which occurs at less than 37 completed weeks of gestation. It is classified as extremely preterm $(<28$ weeks), very preterm $(28$ to $<$ 32 weeks), and moderate to late preterm (32 to < 37 weeks). Likewise preterm birth can be categorized on the basis of birth weight. Neonates weighting less than $2500 \mathrm{~g}$ are classified as low birth weight (LBW), $<1500 \mathrm{~g}$ are very low birth weight $(\mathrm{VLBW})$ and $<1000 \mathrm{~g}$ are extremely low birth weight (ELBW). Preterm birth can also be spontaneous or provider initiated (induced). Spontaneous preterm birth is commencement of labor with intact or pre labor rapture of membrane and birth before

\footnotetext{
* Correspondence: waktasuabe@gmail.com

${ }^{1}$ School of Nursing and Midwifery, College of medicine and health sciences, Hawassa University, Hawassa, Ethiopia

Full list of author information is available at the end of the article
}

37 weeks of gestation. Spontaneous onset of labor accounts for $65-70 \%$ of all preterm births and provider initiated for $30-35 \%$ [1].

The rate of preterm birth is escalating globally and ranges from 5 to $7 \%$ in developed countries and significantly higher in least developed countries. Of the global 135 million live births, 14.9 million (11.1\%) babies were born preterm in 2010. More than $60 \%$ of preterm births occurred in Sub-Saharan Africa and 9.1 million (12.8\%) in south Asia [2].

The rate of preterm birth in Southeast Nigeria rose from $9.8 \%$ in 2009 to $17.1 \%$ in 2013 after peaking at $23 \%$ in 2012. Approximately $57 \%$ of preterm births were spontaneous preterm births while provider-initiated births occurred in $43 \%$ of them. In Gondar University hospital, Northwest Ethiopia about one in seven adverse birth outcomes (14.3\%) was found to be preterm birth and in 
Mettu Karl hospital, Southwestern Ethiopia, the recorded rate of preterm delivery in mothers having pregnancy related hypertension was $31.4 \%$ [3-5].

Preterm births have different causes and risks of mortality, morbidity, impaired growth, and non-communicable diseases. Thus, being born preterm predisposes infants to higher risks of chronic diseases and mortality later in life. Specially, infants born before 32 weeks of gestation are at high risk of adverse health outcomes [6-12]. This study aimed to contribute in identifying factors associated with spontaneous preterm birth in Addis Ababa Public hospitals having Neonatal Intensive Care Unit from 2011 to 2015.

\section{Methods}

Cross sectional study design was applied for this study. From the six public hospitals having neonatal intensive care unit in Addis Ababa, three of them were selected with simple random sampling by lottery method. The sample was proportionally allocated to each three hospitals based on their number of preterm admissions to their respective neonatal intensive care unit. The medical records of the preterm neonates were selected from the registry log book of the neonatal intensive care unit using systematic sampling. The medical record of the preterm neonate admitted from referral within the three selected hospital was excluded to reduce chance of repetition. Retrospective data were collected from the five years admissions of preterm births to neonatal intensive care unit. Data was collected by using structured, pretested checklist from the selected patient's medical records. The checklist was adopted and modified from different related studies [2, 5, 13-21].

Data coding and entry was accomplished using EpiData 3.1 and exported to SPSS version 22. Data cleaning, recoding and analysis were performed with this SPSS. Bivariate logistic regression analysis was done after dichotomizing the dependent variables with coding ' 1 ' for being spontaneous preterm birth and '0' for not being spontaneous preterm birth. Multivariate logistic regression analysis was performed to control confounding factors in the association. $P$-value of $<0.05$ was used to express statistical significance of the variables. Sentence, table of frequency and graphs were used present result of the study.

\section{Results}

From total 23,115 admissions to NICU, preterm accounts 3732 giving Prevalence of preterm birth from neonatal intensive care unit admission $16.15 \%$. A total of 384 preterm neonates' medical records having both maternal and the neonate's histories were involved in this study and all data were used for analysis.

The mean age of the mothers was $26.09( \pm 4.772908$ SD) which ranges of 14 to 43 and 26 was the median age. Majority of the mothers $(51.7 \%)$ were above the mean age $(\geq 26)$ where as $48.3 \%$ were younger than 25 years. One hundred ninety five (50.8\%) and 203 (52.9\%) were primigravida and primipara respectively. Spontaneous Vaginal delivery was the commonest (90.1\%) immediate previous mode of delivery for those who have ever given births previously (Fig. 1). For the current (through which the preterm baby born) mode of delivery spontaneous vaginal accounts for 259 (67.4\%), cesarean section 121 (32.5\%) and instrumental delivery accounts about 4 (1\%). In addition, $156(40.6 \%)$ of the mothers have been diagnosed at least with one medical problem during the current pregnancy and 228 (59.4\%) were not. From these, hypertension stands for 664 (2.3\%), Premature rupture of membrane for 47 (30.1\%), HIV for 24 (15.4\%), ante-partum hemorrhage (APH) for $13(8.3 \%)$, Chorioamnoitis for $12(7.7 \%)$, diabetes for 4 (2.6\%), and others for 7 (4\%).

One hundred ninety six (51\%) of the preterm births were male and $188(49 \%)$ were female neonates. Two hundred fifty four $(66.1 \%)$ were spontaneous preterm births. The minimum and maximum gestational age at birth of preterm births were 24 and 36 weeks respectively with mean gestational age of 32.45 weeks $( \pm 2.903$ $\mathrm{SD)}$ (Fig. 2). The first minute APGAR score of the preterm neonates was found to range 1 to 9 with mean of 5.64 and standard deviation of 1.592 where 261 (68\%) and $123(32 \%)$ were it the category of low (0-6) and normal (7-10) APGAR score respectively. According to finding of this study, 270 (70.3\%) of preterm births' weights were appropriate for their gestational age (AGA), 109 (28.4\%) were small for their gestational age (SGA) and few [5 (1.3\%)] were under category of large for gestational age (LGA).

In bivariate analysis; compared to mothers older than 26 years old, those younger than 25 years were 19.5\% more likely to give spontaneous preterm birth ( $\mathrm{RR}=$ $1.195, P=0.015$, OR $=1.702$, 95\% CI: $1.108,2.613)$. Spontaneous preterm births had an odds of being born to HIV mothers that are 3.828 times the odds of those induced (non-spontaneous) preterm birth $(P=0.008$, OR $=3.828$, 95\% CI: $1.428,10.258)$. Mothers who experienced premature rupture of membrane more likely $(P=$ $0.000, \mathrm{OR}=5.645,95 \% \mathrm{CI}: 2.589,12.309)$ gave spontaneous preterm birth. Other variables like parity, gravidity, multiple pregnancies, outcome of immediate previous pregnancy, time and mode of previous delivery had not shown significant association with spontaneous preterm birth in this study.

In multivariate analysis, only hypertension during pregnancy $[P=0.001$, AOR $=0.182,95 \% \mathrm{CI}:(0.067,0.493)]$ and maternal HIV infection $[P=0.041$, AOR $=3.40895 \% \mathrm{CI}$ : $(1.048,11.079)]$ remained associated with spontaneous preterm birth and other variables turned insignificant in multivariate analysis. Those mothers who were diagnosed 
$6.6 \%(12)$

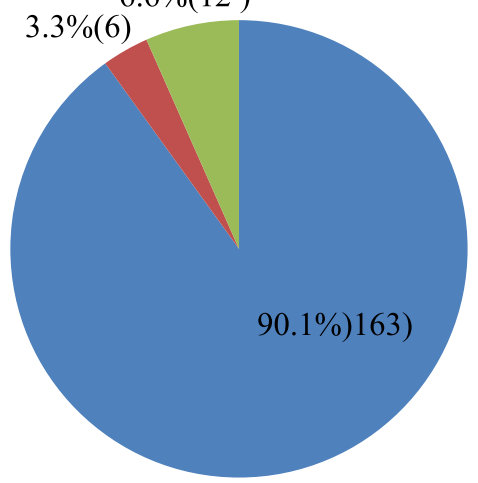

- Spontaneous Vaginal

- Cesarean Section

Instrumental

Fig. 1 Immediate Previous mode of delivery, Addis Ababa, Ethiopia, April, 2016

with hypertension during pregnancy less likely gave spontaneous preterm birth than who had no history of hypertension during pregnancy and HIV positive mothers gave spontaneous preterm more likely than HIV negative mothers (Table 1).

\section{Discussion}

Prevalence of preterm birth in NICU admission in this study (16.5\%) is higher than that of Gondar university hospital and lower than that of Mettu Karl hospital. The reason for this variation might be methodological differences employed in these previous studies [3,5]. Majority of the preterm births (66.1\%) were spontaneous and only few were induced deliveries. This finding is similar with global report and study in Southeast Nigeria in which spontaneous preterm accounts greater proportion [4, 22]. Majority of the preterm birth's mothers $(51.7 \%)$ in this study were above the mean age ( $\geq 26$ years), but in rural South Africa and Malawi, the greater proportion of the mothers were younger than 20 years. Methodological and socio-economic variation can be the reason for this difference. Unlike study in Nova Scotia which reported older age to be at higher risk to give spontaneous preterm birth, mothers who were younger than 25 years in this study were at higher risk to give spontaneous preterm birth in bivariate analysis $(\mathrm{RR}=$ $1.195, P=0.015$, OR $=1.702$, 95\% CI: $1.108,2.613)$. Socioeconomic difference with methodology of the study can be reason into account for this variation. But finding in this study is in line with evidence of study from Taiwan for risk of preterm birth. Even though age classification for the association varies, study in Malawi also supports this as younger women are at high risk of giving preterm birth [23, 24]. As global report indicated [22], premature rupture of membrane was associated with spontaneous preterm birth. Also this study verified that mothers who developed premature rupture of membrane had greater odds of giving spontaneous preterm birth which is 5.645times odds of those who haven't developed premature rupture of membrane. But it is left on the border of significance in multivariate analysis. Although report of preterm delivery for immediate previous pregnancy was high (24.9\%) like that of report from Malawi, statistical significance was not observed in this

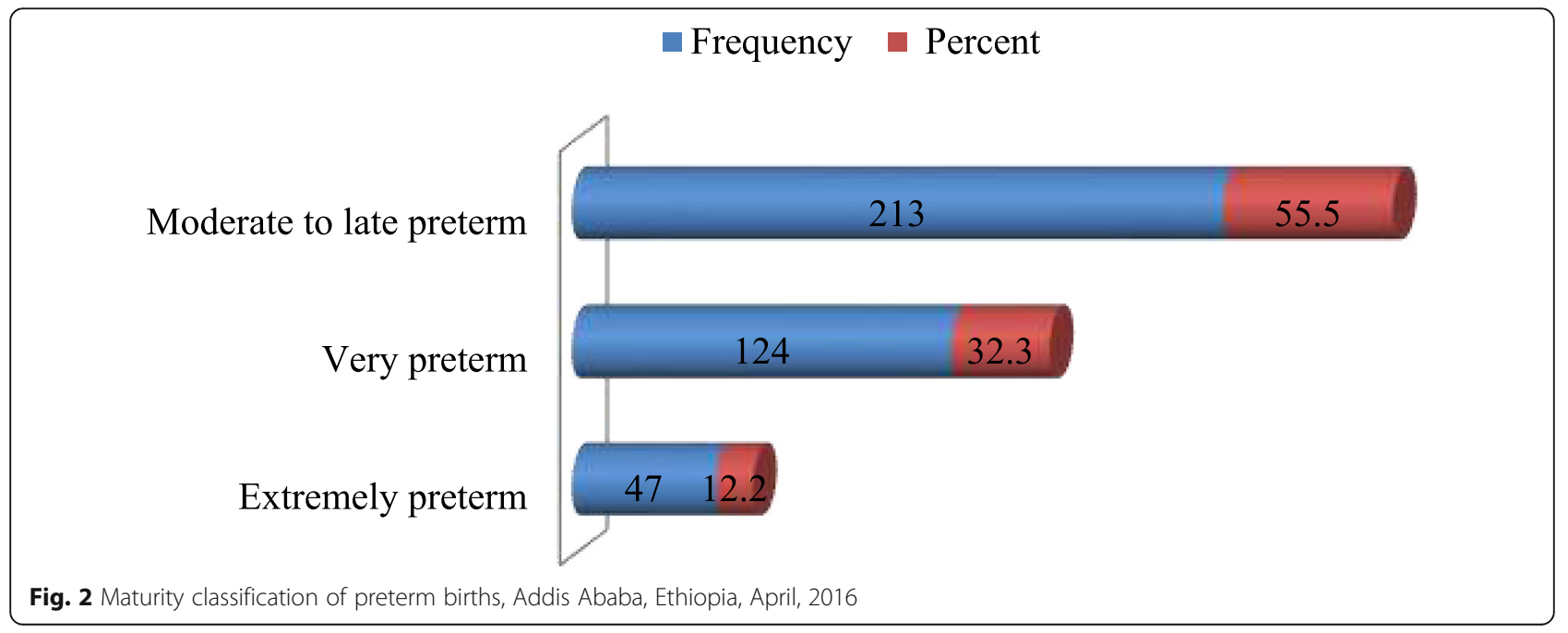


Table 1 Multivariate Analysis of factors associated with Spontaneous Preterm birth, Addis Ababa, Ethiopia, April 2016

\begin{tabular}{|c|c|c|c|c|c|}
\hline \multirow[t]{2}{*}{ Characteristics } & \multicolumn{2}{|c|}{ Spontaneous preterm } & \multirow[t]{2}{*}{ S.E. } & \multirow{2}{*}{$\begin{array}{l}P- \\
\text { value }\end{array}$} & \multirow[t]{2}{*}{ AOR( 95\% C.I) } \\
\hline & Yes: \# (\%) & No: \# (\%) & & & \\
\hline \multicolumn{6}{|l|}{ Gravidity } \\
\hline$<1$ & 135(69.2) & $60(30.8)$ & 1.579 & 0.686 & $0.528(0.024,11.659)$ \\
\hline$\geq 2^{\mathrm{a}}$ & $119(63.0)$ & $70(37.0)$ & & & 1 \\
\hline \multicolumn{6}{|l|}{ Parity } \\
\hline$<1$ & $141(69.5)$ & $62(30.5)$ & 1.706 & 0.682 & $2.010(0.071,56.894)$ \\
\hline$\geq 2^{a}$ & $113(62.4)$ & 68(37.6) & & & 1 \\
\hline \multicolumn{6}{|c|}{ Time of immediate previous delivery } \\
\hline 12 months ago & 29(65.9) & 15(34.1) & 0.928 & 0.699 & $1.432(0.232,8.829)$ \\
\hline 36 months ago ${ }^{a}$ & $8(47.1)$ & $9(52.9)$ & & & 1 \\
\hline \multicolumn{6}{|l|}{ Multiple pregnancy } \\
\hline Yes & $44(60.3)$ & 29(39.7) & 0.545 & 0.904 & $1.068(0.367,3.109)$ \\
\hline $\mathrm{No}^{\mathrm{a}}$ & $210(67.5)$ & 101(31.5) & & & 1 \\
\hline \multicolumn{6}{|c|}{ Maternal HIV infection } \\
\hline Yes & 18(75.0) & $6(25.0)$ & 0.601 & $0.041^{b}$ & $3.408(1.048,11.079)$ \\
\hline $\mathrm{No}^{\mathrm{a}}$ & $58(43.9)$ & $74(56.1)$ & & & 1 \\
\hline \multicolumn{6}{|c|}{ Hypertension during pregnancy } \\
\hline Yes & 13(19.7) & $53(80.3)$ & 0.509 & $0.001^{b}$ & $0.182(0.067,0.493)$ \\
\hline $\mathrm{No}^{\mathrm{a}}$ & 63(70.0) & $27(30.0)$ & & & 1 \\
\hline \multicolumn{6}{|l|}{ PROM } \\
\hline Yes & $24(51.1)$ & 23(48.9) & 0.530 & 0.066 & $2.646(0.937,7.476)$ \\
\hline $\mathrm{No}^{\mathrm{a}}$ & $52(47.7)$ & $57(52.3)$ & & & 1 \\
\hline \multicolumn{6}{|l|}{ Age of mothers } \\
\hline$<25$ & 135(72.2) & $52(27.8)$ & 0.696 & 0.919 & $0.932(0.238,3.645)$ \\
\hline$\geq 26^{a}$ & $119(60.4)$ & 78(39.6) & & & \\
\hline
\end{tabular}

S.E. Standard error, AOR Adjusted Odds ratio

${ }^{\mathrm{a}}$ Reference, ${ }^{\mathrm{b}}$ Significant association

study [15]. Mothers with HIV had greater odds of giving spontaneous preterm birth which shown significant statistical association in both bivariate and multi-variate analysis $(P=0.041$, AOR $=3.408, \mathrm{CI}: 1.048,11.079)$. Similarly, HIV disease significantly associated with increased risk of giving preterm birth in Tanzania [25].

\section{Conclusion}

Age of mothers younger than 25 years, having at least one medical disorder during pregnancy, maternal HIV infection, hypertension during pregnancy, premature rupture of membrane from which maternal HIV infection and hypertension during pregnancy remained significant in multivariate analysis were factors found to have significant association with spontaneous preterm birth.

\section{Abbreviations}

AGA: Appropriate for gestational age; AOR: Adjusted Odd ratio; Cl: Confidence Interval; ELBW: Extremely low birth weight; HIV: Human Immune-deficiency Virus; LBW: Low birth weight; LGA: Large for gestational age; OR: Odds Ratio; RR: Relative Risk; SD: Standard Deviation; SGA: Small for gestational age; VLBW: Very low birth weight

\section{Acknowledgements}

Addis Ababa University deserves the gratitude for academic support of this research. We also extend our gratitude to Black lion specialized hospital, Gandhi memorial hospital and Zewditu memorial hospital for their cooperation. Dr. Petros Jirata is also remarkable for his review and support in this research.

\section{Availability of data and materials}

The datasets used and/or analyzed during the current study are available from the corresponding author on reasonable request.

\section{Consent to publish}

Not applicable in this section.

\section{Authors' contributions}

ATD contributed to conception and design of the study, analysis and interpretation of data. He has also involved in supervision of data collection, entry and coding with the other authors. AC has contributed to conception and design of the study. She has also involved in data entry and analysis with the other authors. TMB has contributed to conception of the study. He has also involved in data entry, analysis and report write up with the other authors. GGT has contributed to design of the study. He has also involved in supervision of data collection, data 
entry, analysis and report write up with the other authors NB The manuscript has been read and approved by all authors.

\section{Authors' information}

Ababe Tamirat Deressa is lecturer and researcher at Hawassa University College of medicine and health sciences. He graduated with Bachelor of Science in Nursing, Master of Science in child health and pediatric nursing and fellow in master of art in Organizational leadership. Dr. Amsale Cherie is assistant professor at Addis Ababa University College of medicine and health sciences. She is lecturer and researcher nurse with doctor of philosophy in public health. Teshome Melese Belihu is lecturer and researcher at Hawassa University College of medicine and health sciences. He graduated with Bachelor of Science in Midwifery and Master of Science in maternity and reproductive health nursing. Gemechu Ganfure Tasisa is lecturer and researcher at Madda Walabu University. He graduated with Bachelor of Science in Midwifery and Master of Science in Child health and pediatric nursing.

\section{Ethics approva}

Institutional review board of Addis Ababa University was ethics committee that handled the approval of this study. Letter of correspondence from Addis Ababa University, school of Allied health sciences department of nursing and midwifery was written to Black lion specialized hospital and Addis Ababa regional health office for permission of both Gandhi and Zewditu memorial hospitals after which cooperation letter was sent for the two hospitals. Besides, information sheet designed to elaborate the study was attached to the data collection tool. However, informed consent was not specifically designed since data was collected from secondary source. After getting permission from the medical director, neonatology and pediatric department of the three hospitals was requested to confirm the applicability of this study and letter was written to NICU and medical record office of the respective hospital from neonatology and pediatric department. Following these, searching and obtaining of the selected samples' medical record was processed with assigned person. Finally, strict care for the patient's medical record and confidentiality not to take patient identifications except the identified variables for the neonate was involved throughout the time of data collection up to respect return of medical records on the end of tasks.

\section{Competing interests}

The authors had no personal or financial conflict of interest.

\section{Publisher's Note}

Springer Nature remains neutral with regard to jurisdictional claims in published maps and institutional affiliations.

\section{Author details}

${ }^{1}$ School of Nursing and Midwifery, College of medicine and health sciences, Hawassa University, Hawassa, Ethiopia. ${ }^{2}$ Department of Nursing and midwifery, School of Allied health sciences, Addis Ababa University, Addis Ababa, Ethiopia. ${ }^{3}$ School of health Sciences, College of medicine and health sciences, Hawassa University, Hawassa, Ethiopia. ${ }^{4}$ Midwifery department, School of health sciences, MaddaWalabu University, Bale Robe, Ethiopia.

\section{Received: 4 August 2017 Accepted: 30 July 2018}

\section{Published online: 13 August 2018}

\section{References}

1. WHO: World Health Organization (WHO). International statistical classification of diseases and related health problems. Geneva: WHO Available from: https://www.cdc.gov/nchs/data/dvs/Nolume-1-2005.pdf. Accessed 25 Oct 2015

2. Blencowe H, Cousens S, Chou D, Oestergaard M, Say L, Moller A, et al. Born too Soon : the global epidemiology of 15 million preterm births. Reprod Health. 2013;10(Suppl 1):1-14.

3. Seyom E, Abera M, Tesfaye M, Fentahun N. Maternal and fetal outcome of pregnancy related hypertension in Mettu Karl referral hospital. Journal of Ovarian Research. 2015:4-10.
4. Anthony C, llechukwu G, Nkwo PO, Mba SG, Asinobi IN. Prevalence and perinatal mortality associated with preterm births in a tertiary medical center in south East Nigeria. Int J Women's Health. 2014;62014:881-8.

5. Adane AA, Ayele TA, Ararsa LG, Bitew BD. Adverse birth outcomes among deliveries at Gondar University Hospital , Northwest Ethiopia. BMC Pregnancy and Childbirth. 2014;14(1):1-8.

6. Crump C, Sundquist K, Sundquist J, Winkleby MA. Gestational age at birth and mortality in young adulthood. JAMA. 2011;306:1233-40.

7. Crump C, Sundquist K, Winkleby MA, Sundquist J. Early-term birth (37-38 weeks) and mortality in young adulthood. Epidemiology. 2013;24:270-6.

8. Beck S, Wojdyla D, Say L, Betran AP, Merialdi M, et al. The world wide incidence of preterm birth: a systematic review of maternal mortality and morbidity. Bull World Health Organ. 2010;88:31-8.

9. Blencowe H, Cousens S, Oestergaard MZ, Chou D, Moller AB, et al. National, regional, and worldwide estimates of preterm birth rates in the year 2010 with time trends since 1990 for selected countries: a systematic analysis and implications. Lancet. 2013;379:2162-72.

10. Lee ACC, Katz J, Birth CS. National and regional estimates of term and preterm babies born small for gestational age in 138 low-income and middle-income countries in 2010. Lancet Glob Health. 1(1):2010, e26-36.

11. Van den Broek N, Ntonya C, Kayira E, White S, Neilson JP. Preterm birth in rural Malawi: high incidence in ultrasound-dated population. PLOS Medicine. 2011;20:3235-7.

12. EURO-PERISTAT project in collaboration with SCPE, EUROCAT and EURONEOSTAT. Better statistics for better health for pregnant women and their babies in 2004. In: European Perinatal Health Report; 2008.

13. Debelew GT, Afework MF, Yalew AW. Determinants and Causes of Neonatal. Mortality in Jimma Zone, Southwest Ethiopia : A Multilevel Analysis of Prospective Follow Up Study. PLOS ONE. 2014;9(9):e107184.

14. Weng Y, Yang C, Chiu Y. Risk assessment of adverse birth outcomes in relation to maternal age. PLoS One. 2014;9(12):1-16.

15. Broek NR, Van Den J-b R, Neilson JP. Factors Associated with Preterm, Early Preterm and Late Preterm Birth in Malawi. PLOS ONE. 2014:9(3):e90128.

16. Gladstone M, White S, Kafulafula G, Neilson JP, Van Den Broek N. Post neonatal Mortality, Morbidity, and Developmental Outcome after Ultrasound- Dated Preterm Birth in Rural Malawi : A Community-Based Cohort Study. PLoS Med. 2011:8(11):1-11.

17. NIH Public Access. Risk of spontaneous preterm birth in relation to maternal exposure to intimate partner violence during pregnancy in Peru. Maternal Child Health J. 2014;17(3):485-92.

18. Santos IS, Matijasevich A, Domingues MR, Barros AJD, Victora CG, Barros FC. Late preterm birth is a risk factor for growth faltering in early childhood : a cohort study. BMC Pediatr. 2009;8:1-8.

19. Pfinder $M$, Kunst $A E$, Feldmann $R$, Van Eijsden M, Vrijkotte TGM. Preterm birth and small for gestational age in relation to alcohol consumption during pregnancy : stronger associations among vulnerable women ? Results from two large western-European studies. BMC Pregnancy and Childbirth. 2013:13(1):1.

20. Kozuki N, Lee ACC, Silveira MF, Victora CG, Adair L, Humphrey J, et al. The associations of birth intervals with small-for-gestational-age, preterm, and neonatal and infant mortality : a meta-analysis. BMC Public Health. 2013; 13(Suppl 3):S3.

21. Kariuki S, Kuile F, Marchant T, Willey B, Katz J, Lusingu J, et al. Neonatal Mortality Risk Associated with Preterm Birth in East Africa, Adjusted by Weight for Gestational Age : Individual Participant Level Meta-Analysis. PLOS MEDICINE. 2012;9(8):e1001292.

22. Barros FC, Bhutta A, Batra M, Hansen TN, Victora CG, Rubens CE. Global report on preterm birth and stillbirth ( 3 of 7 ): evidence for effectiveness of interventions. BMC Pregnancy and Childbirth 2010:10(Suppl1):1-36.

23. Joseph KS, Fahey J, Shankardass K, Allen VM, Campo PO, Dodds L, et al. Effects of socioeconomic position and clinical risk factors on spontaneous and iatrogenic preterm birth. BMC Pregnancy and Childbirth. 2014;14(1):1-9.

24. Kozuki N, Lee ACC, Silveira MF, Sania A, Vogel JP, Adair L, et al. The associations of parity and maternal age with small-for-gestational-age, preterm, and neonatal and infant mortality: a meta-analysis. BMC Public Health. 2013:13

25. Zack RM, Golan J, Aboud S, Msamanga G, Spiegelman D, Fawzi W. Risk Factors for Preterm Birth among HIV-Infected Tanzanian Women: A Prospective Study. Hindawi Publishing Corporation. 2014 